\title{
Correspondence
}

Editor: Ian Pullen

Contents: Psychiatry is more than a science/ Blood-letting in bulimia nervosa/Neglect of anger in Western psychiatry/The ethics of resource allocation/Personality disorder and self-report questionnaire/Computerised assessment of depression in the medically ill/Community Treatment Order in Australia/Insight in psychosis/Down's syndrome, longevity, and Alzheimer's disease/Association of schizophrenia and Duchenne muscular dystrophy.

\section{Psychiatry is more than a science}

SiR: Professor Cawley's paper (Journal, February $1993,162,154-160)$ is interesting in very many respects. I am surprised, however, at the paper's tendency to present obvious notions, as if Professor Cawley had just come up with totally original concepts.

Professor Cawley "insists" in his paper that philosophy is the missing dimension in psychiatry. "Among the humanities", he states, "the one subject that may prove to have relevance to appropriate theory and competent practice is philosophy". In other words, Professor Cawley believes that philosophy and I assume he means Western philosophy - will not only provide answers to our many perplexing questions, but also will enable us to practise psychiatry more competently! This, of course, is manifestly misguided, for it reveals a lack of apprehension of the limits of philosophical knowledge.

According to Bertrand Russell (1912):

"Philosophy is to be studied, not for the sake of any definite answers to its questions, since no definite answers can, as a rule, be known to be true, but rather for the sake of the questions themselves; because these questions enlarge our conception of what is possible, enrich our intellectual imagination, and diminish the dogmatic assurance which closes the mind against speculation; but above all because, through the greatness of the universe which philosophy contemplates, the mind also is rendered great, and becomes capable of that union with the universe which constitutes its highest good."

The value of philosophy, therefore, lies in the profound beneficial effects, on our inner life, of speculation and contemplation.
We should certainly study philosophy, but not with the hope that it will answer our questions about mental illness, or make us more competent psychiatrists. We should study it because it will "enlarge our conception of what is possible", for this is of crucial importance to the success of our endeavours. The greatest problem that we face, as scientists, is that we have always operated from the perspective of preconceived notions, picking and choosing what to accept as true and what to reject as false, even when we secretly suspect that our viewpoints are mistaken. Our lack of humility prevents us from admitting our ignorance. Given the advantage of an open mind, we will know what is true and what is not. Philosophy will help us overcome our prejudice against the truths of life.

I commend the efforts of our College's Philosophy Interest Group, and would like to encourage its membership to balance the speculative intellectualisation which is the essence of philosophy, with equal interest in psychical (i.e. parapsychological) research.

Russell, B. (1912) The Problems of Philosophy. Oxford: Oxford University Press.

\section{Grovelands Priory Hospital}

I. O. AZuONYE

\section{The Bourne}

Southgate

London N146RA

SIR: I support Professor Cawley's hypothesis that; "Psychiatry depends on science and considerably more besides" (Journal, February 1993, 162, 154160). He asks; "Is it correct to say that there is a substantial non-science component in understanding and treating mental illness?" A work published 20 years ago answers the question in the affirmative, and should be a prescribed philosophical text for trainee psychiatrists.

Maurice O'Connor Drury was a psychiatrist at St Patrick's Hospital, Dublin, from 1947 until his death as senior consultant in 1976. He was a friend and pupil of the philosopher Wittgenstein, and in 1973 he published a collection of essays to some extent inspired by him (Drury, 1973). Perhaps the main 